\title{
VISUALIZAÇÃO DA INFORMAÇÃO E PRÁTICA SOCIAL: NOVOS CENÁRIOS PARA ATUAÇÃO DO DESIGN
}

\author{
Júlia Rabetti Giannella \\ Universidade de São Paulo \\ juliagiannella@gmail.com
}

\begin{abstract}
Resumo: A visualização da informação, uma manifestação do Design da Informação, designa processo cujo objetivo é facilitar a compreensão de grande quantidade de dados ao tornar evidentes relações de semelhança, ordem e proporcionalidade a eles subjacentes. O presente artigo destaca cenário de dimensão social para a prática da visualização da informação demarcado pela sobrecarga de dados e pelo movimento de descentralização comunicacional que ascendem na sociedade contemporânea e potencializam a emergência de novos formatos midiáticos. No contexto da estrutura em rede, dos formatos abertos e da inteligência coletiva, o uso das técnicas e conceitos da visualização da informação reforçam a investigação e compreensão de temas oriundos da esfera público-social. A visualização da informação contribui para a transformação dos dados brutos em uma interface visual e interativa na qual diversos interagentes assumem posturas ativas, coletivas e cidadãs na produção de conhecimento de relevância social.
\end{abstract}

Palavras-chave: Design da Informação, Visualização da Informação, Prática social, Dados abertos, Inteligência coletiva.

\begin{abstract}
Information visualization, which is a manifestation of the Information Design field, means a process in which the goal is to facilitate the understanding of a large amount of data, revealing similarity, order and proportionality relationships underlying it. This article highlights a socially oriented setting for the practice of information visualization, which is outlined by data overload and a decentralized communication movement that regard contemporary society and enhance the emergence of new media formats. In the context of network structure, open formats and collective intelligence, the use of techniques and concepts from information visualization research strengthen the comprehension of issues arising from the public social sphere. Information visualization contributes to the transformation of raw data into a visualinteractive interface in which many interactors assume active, collective and citizenly attitudes projecting social relevant knowledge production.
\end{abstract}

Keywords: Information Design, Information Visualization, Social practice, Open data, Collective intelligence. 


\section{INTRODUÇÃO}

O Design da Informação pode ser compreendido como disciplina que atua no processo comunicacional facilitando a compreensão de uma mensagem ou como atividade que exerce ações em torno da organização, planificação e apresentação de determinadas informações.

Horn, ao defender que o Design da Informação é uma das mais recentes manifestações da Comunicação, o definiu como: "[...] a arte ou a ciência de preparar a informação de maneira que ela possa ser usada pelos indivíduos com mais eficiência e efetividade." (HORN, 2000, p. 15, tradução nossa). O autor identifica três objetivos para o Design da Informação:

a) desenvolver documentos compreensíveis para assimilação rápida e precisa, e que sejam facilmente convertidos em ações efetivas;

b) projetar interações fáceis, naturais e prazerosas para interfaces homemcomputador;

c) auxiliar pessoas a encontrar caminhos em espaços tridimensionais com facilidade, especialmente em ambientes urbanos, mas também em espaços virtuais.

Tais objetivos podem ser encaminhados para uma finalidade mais geral e ampla: "[...] assegurar a efetividade da comunicação mediante a facilitação dos processos de percepção, leitura, compreensão, memorização e uso da informação apresentada" (FRASCARA, 2000, p. 11, tradução nossa). Com essas palavras, Frascara sugere que a essência do Design de Informação é necessariamente centrada no usuário e em suas necessidades, o que faz com que o objetivo primordial de sua atividade desloque-se da produção de objetos em si mesmos para a "... criação de meios que sirvam para as pessoas aprenderem, recordarem, atuarem, interagirem (com objetos, pessoas e informações), realizarem seus desejos e satisfazerem suas necessidades (FRASCARA, 2000, p. 23, tradução nossa).

Justamente por que são produzidos para serem usados e gerarem sentido - o que estabelece sua intencionalidade pragmática - percebemos um quarto possível e específico objetivo para os processos e produtos derivados do Design da Informação, que estabelece sua dimensão social e que procuraremos enfatizar neste trabalho: 0 Design da Informação possibilita explorar e comunicar dados complexos por meio de representações visuais, de modo a produzir significações esclarecedoras e, em última instância, proporcionar ações efetivas para assuntos dos mais variados interesses, dos quais destacamos temas de relevância público-social como saúde, meio ambiente, desenvolvimento humano, políticas públicas, direitos civis, etc.

O processo do Design da Informação ocorre em dois momentos distintos: a organização da informação (o conteúdo e suas unidades de sentido, textos e imagens) e a codificação e implementação de sua apresentação visual. Essas tarefas requerem habilidades e conhecimentos interdisciplinares para processar, organizar e apresentar a informação em formas linguísticas (escrita) e não linguísticas (a imagem em seu sentido mais amplo) e resultam em uma multiplicidade de sistemas texto-visuais, como por exemplo projetos gráficos, sinalizações, design instrucional e, finalmente, a visualização da informação. Esse produto do Design da Informação, que não tem fim em si mesmo, pode ser compreendido também como uma potencial tecnologia do design para a exploração, análise e comunicação de dados com intuito de favorecer e ampliar a discussão de temas de impacto social. 
Uma tentativa de teorização sobre a disciplina estabelece uma perspectiva interessante para o Design da Informação: não há nada de natural na informação. Ela é sempre construída (Dervin, 2000, p. 36). A autora assim propõe o conceito de sensemaking, isto é, um processo comunicacional e bidirecional no qual os indivíduos, individual ou coletivamente, realizam seus processos de produção de sentido. Como consequência, "[...] o design da informação é, em efeito, metadesign: design sobre design, design para ajudar indivíduos a fazer e desfazer suas próprias informações, seus próprios sentidos." (DERVIN, 2000, p. 43, tradução nossa). Essa abordagem a respeito do Design da informação, embora possa ser questionada em determinados contextos comunicacionais, sobretudo aqueles mais tradicionais como o Jornalismo, aproxima-se da forma como pretendemos abordar a visualização da informação: uma tecnologia de representação visual de conceitos abstratos que pode ser utilizada para explorar, analisar e comunicar informação de interesse social, e, consequentemente, promover sentido e, em última instância, decisões fundamentadas. A perspectiva de Dervin encontra eco na defesa de Frascara (2001, p. 9) de que as mensagens produzidas pelo Design da Informação não são apenas para serem comunicadas em um modelo unidirecional, mas sim para gerarem interpretações, seja a de um analista observando significações e relações entre dados em um gráfico construído por ele mesmo, seja a de um leitor diante de um mapa de dados buscando extrair sentido da relação entre os dados representados. Nessa mesma linha de pensamento, dois conceitos interligados no âmbito das atividades relacionadas ao Design da Informação são distinguidos: edificação e comutatividade (JACOBSON, 2000, p.2). O primeiro termo refere-se ao processo de iluminação de informações complexas estabelecido na direção emissor>receptor, com o objetivo de tornar aqueles que analisam ou consomem o conteúdo pessoas mais esclarecidas a respeito de determinado assunto. O segundo termo destaca a ação mútua e dialógica entre os interagentes do processo comunicacional (emissor<>usuário) na produção de sentido, e envolve questões do meio, do contexto e dos indivíduos. Ambas as lógicas coexistem nos produtos derivados do Design da Informação, e é nosso objetivo evidenciar o caráter ao mesmo tempo edificante e gerador de sense-making que torna a visualização da informação um efetivo processo para a compreensão de assuntos de relevância social.

\section{VISUALIZAÇÃO DA INFORMAÇÃO}

A visualização da informação corresponde a uma modalidade de organização e apresentação visual da informação e pertence ao universo maior constituído pelo Design da Informação. Em seu sentido lato, designa um processo cujo objetivo é facilitar a compreensão de uma grande quantidade de dados ao tornar evidentes relações de semelhança, ordem e proporcionalidade subjacentes a eles. A visualização da informação constitui-se em um campo interdisciplinar - com base em saberes específicos do Design da Informação, do Design de Interação, da Percepção Visual e da Comunicação Social, entre outros - com potencial de proporcionar à sociedade novos usos da informação bem como modos alternativos de aquisição e produção de conhecimento em diversas áreas de atuação.

Terminologias e conceituações a respeito da visualização da informação não são convergentes, o que pode ser atribuído ao fato de terem sido desenvolvidas por disciplinas distintas, a saber, Engenharia, Estatística, Ciências da Computação, Design da Informação e Comunicação. Destacamos termos e conceitos que, independentemente 
das áreas em que foram formulados, nos ajudam a caracterizar e analisar questões relativas às estruturas visuais e interativas desta modalidade comunicativa: visualização da informação (CARD et al., 1999; CAIRO, 2008; 2013; DÜRSTELER, 2003; FEW, 2009), visualização esquemática (COSTA, 1998), gráficos da informação (BERTIN, 2010) diagrama (FRASCARA, 2001), gráficos de dados (CLEVELAND, 1994; TUFTE, 1983). Não obstante as diferenças terminológicas, a abstração é elemento essencial e comum a todas estas conceituações. A abstração consiste, em contraponto à figuração, em representações visuais de baixo nível de iconicidade (COSTA, 1998, p. 104), isto é, menor ou nula relação indicial com o seu respectivo referente - como, por exemplo, mapas de dados, diagramas, gráficos e esquemas.

Em pesquisas mais recentes, podemos observar certo adensamento em torno do termo visualização da informação, assim como o avanço para a teorização da especialidade, para além dos aspectos visuais de esquematização. Fatores como o surgimento do computador e a expansão da internet trouxeram à tona questões ligadas à possibilidade de uso de base de dados, uso de softwares mais sofisticados para a manipulação dos mesmos, representações visuais multidimensionais (com muitas variáveis informativas) e o uso de suportes digitais para a produção, circulação e apresentação do conteúdo. Nessa linha de pensamento, as contribuições de Card et al. (1999) e Few (2009) são fundamentais. Para os autores a visualização da informação configura-se, em sentido mais estrito, como o "uso de representações visuais interativas de dados abstratos, auxiliado por um computador, para amplificar a cognição" (CARD et al., 1999, p.6-7). Portanto, para os autores o termo visualização não deve ser aplicado às configurações apresentadas e acessíveis em dispositivos impressos como o papel, por exemplo.

Para o dicionário Aurélio visualizar é: “1) Tornar visível, mediante manobra ou procedimento; 2) Formar ou conceber uma imagem visual mental de (algo que não se tem ante os olhos no momento)." Dessa forma, também em termos terminológicos, é possível deduzir que em seu sentido mais amplo, a visualização da informação apoia-se fundamentalmente na capacidade humana de produzir e apreender informações por meio de abstrações visuais, e que seu objetivo maior é amplificar a cognição. Com isso também parece concordar Dürsteler (2003) que, após identificar e reunir definições sobre visualização da informação e passar por questões ligadas ao computador e à interatividade, retorna ao sentido mais lato do termo ao defini-lo como "... processo de interiorização do conhecimento mediante a percepção da informação ou, se assim se preferir, mediante a elaboração dos dados" (DÜRSTELER, 2003, p. 22, tradução nossa). Concordamos com a compreensão de que o uso de computadores não estabelece uma relação determinante para que haja visualização da informação, pois sua justificativa maior, dentro da perspectiva comunicacional e geradora de sensemaking, é facilitar a compreensão e descoberta de significados, o que pode ser alcançado dentro das limitações e potencialidades de qualquer suporte.

A subdivisão da categoria visualização em visualização científica e visualização da informação ocorre conforme a natureza dos dados. Para a primeira, é necessário haver espaços físicos e/ou dados físicos (corpo humano, planeta Terra, moléculas, etc.). Para a segunda, é necessário haver informações não físicas, como dados financeiros, dados de negócios, coleção de documentos, conceitos abstratos, etc. (CARD et al., 1999, p. 6-7). Tal diferença conceitual é partilhada por Costa (1998, p. 6281), que associa a visualização científica aos fenômenos invisíveis a olho nu, mas que, 
por meio da mediação de instrumentos como microscópios, raios laser, scanning, etc. podem ser revelados e compreendidos. No entanto, diferentemente de Card et al. (1999), o autor não inclui o computador como requisito fundamental à visualização informativa, enfatizando apenas a necessidade de "[...] critérios de síntese e inteligibilidade com fins comunicacionais." (COSTA, 1998, p.113, tradução nossa).

Few (2009, p. 12) utiliza a expressão visualização de dados como termo guarda-chuva que cobre tanto a visualização da informação como a visualização científica, compreendidas a partir das definições de Card et al. (1999). Assim como os últimos, Few desmembra e define os termos envolvidos na conceituação de visualização da informação e desenvolve um esquema com as atividades, tecnologias e objetivos envolvidos nos processos de visualização:

Quadro 1: Atividades, tecnologias e objetivos da Visualização de dados.

\begin{tabular}{|c|c|l|}
\hline \multicolumn{3}{|c|}{ Visualização de dados } \\
\hline Atividades & $\begin{array}{c}\text { Exploração } \\
\text { Sense-making }\end{array}$ & $\rightarrow$ Comunicação \\
\hline Tecnologias & $\begin{array}{c}\text { Visualização da informação } \\
\text { Visualização científica }\end{array}$ & $\rightarrow$ Representação gráfica \\
\hline Objetivos imediatos & \multicolumn{2}{|c|}{ Compreensão } \\
\hline Objetivos finais & Boas decisões \\
\hline
\end{tabular}

O quadro 1 (FEW, 2009, p. 12, tradução nossa) nos ajuda a compreender a visualização da informação como uma tecnologia de representação gráfica que pode ser observada tanto em uma situação de exploração do conteúdo, na qual um usuário, por exemplo, busca interpretar um conjunto de dados, como em um contexto de comunicação do conteúdo, no qual um jornalista visual, por exemplo, precisa transmitir informações significativas ao leitor. Em ambos os casos, os objetivos devem ser os mesmos: em um primeiro momento, gerar compreensão sobre um determinado fato ou fenômeno e, em um segundo momento, promover boas decisões a partir da compreensão adquirida. Decisões fundamentadas constituem o grau máximo de afetação que o Design pode alcançar. Entretanto, mensurar e qualificar decisões são tarefas subjetivas, de forma que consideramos, no exemplo retratado a seguir, neste artigo, a compreensão como objetivo final da visualização da informação.

\section{O PAPEL SOCIAL DO DESIGN DA INFORMAÇÃO NO CONTEXO DO BIG DATA}

A revista inglesa The Economist publicou, no início de 2010, a previsão do International Data Corp (IDC), empresa especializada em pesquisa de mercado, de que a quantidade de dados digitais gerados naquele ano atingiria 1.200 exabytes, número que poderia ser equiparado à informação contida em 10 bilhões de cópias da mesma publicação. Essa notícia ilustra o fenômeno do Big Data $^{1}$ que, por sua vez, nos alerta sobre o aumento da quantidade de dados disponíveis e acessíveis e a necessidade de ampliar-se o campo da arquitetura e do Design da Informação para que os dados possam ser organizados e gerar sentido (WURMAN, 1991). Diante desse cenário, o

\footnotetext{
${ }^{1}$ Big Data é um termo usado para descrever o acelerado crescimento de dados. Em 2001, o Grupo Gartner, Centro de Pesquisa em Tecnologia da Informação estabelecido em Connecticut, Estados Unidos, definiu os desafios e as oportunidade do crescimento vertiginoso de dados por meio da avalição de três parâmetros: volume crescente (quantidade de dados), velocidade (entrada e saída de dados) e variedade (tipos e fontes de dados).
} 
autor sugere que o grande desafio da era da informação é evitar a ansiedade da informação, isto é, evitar o buraco negro entre o dado em seu estado bruto e o conhecimento efetivo. Essa lacuna é evidenciada no modelo DIKW ${ }^{2}$ (data, information, knowledge, wisdom), no qual os dois extremos da máxima de Wurman (dado e conhecimento) são apresentados.

Dados são produtos de pesquisa, criação, coleta ou descoberta. Constituem o material bruto utilizado na construção de mensagens comunicativas. Para serem compreendidos, precisam ser transformados em informação e apresentados de maneira a revelar algum conteúdo significativo. Essa transformação abrange, no mínimo, dois momentos do Design da Informação: 1) uma organização lógica dos dados e 2) uma apresentação apropriada da estrutura. É exatamente nessa transformação (dados > informação) que o Design assume uma função mediadora, e a visualização da informação intervém ao tornar possível a construção do conhecimento, revelando padrões subjacentes aos dados (DÜRSTELER, 2003, p.24). Conhecimento e sabedoria são etapas pertencentes às esferas dos indivíduos e correspondem a graus diferentes de compreensão das informações apresentadas, processadas e internalizadas por meio de experiências pessoais e intransferíveis. $O$ conhecimento é a compreensão alcançada por meio da experiência pessoal, e implica na construção de interações com indivíduos ou com ferramentas de modo que os padrões e significados em suas informações possam ser percebidos e apreendidos pelos usuários. A sabedoria é uma compreensão profunda do conhecimento adquirido, sendo extremamente íntima e abstrata. O Design não pode criar sabedoria assim como coleta dados e media informações. Finalmente, a sabedoria constitui um nível de compreensão que só pode ser obtido individualmente.

As possibilidades de atuação do Design da Informação são claramente ampliadas no contexto de excesso de dados e da valorização do tempo e da informação evidentes em nossa sociedade. Desta forma, o Design da Informação pode se tornar um caminho decisivo para controlar a chamada explosão da (não) informação e contribuir para a democratização e edificação do conhecimento:

O designer da informação é mediador entre os dados abstratos, que integram uma informação no seu estado bruto, e suas apresentações em informações visualmente significativas, compreensíveis para o leitor. (COSTA, 1998, p. 34, tradução nossa).

Exatamente neste ponto de transformação (dados > informação), vai atuar o Design, ao aplicar sua expertise na redução da complexidade cognitiva e na apresentação da informação por meio de interface que conjugue as fontes de informação, os dados e os leitores (BONSIEPE, 2000, p. 6). O Design da Informação pode ser compreendido, por um lado, como atividade que, para além da organização de informações complexas em uma configuração visual que facilite sua apreensão, também organiza e produz significados; em outras palavras, "[...] seu objetivo é facilitar o metabolismo cognitivo e a assimilação de conhecimento." (BONSIEPE, 2000, p.6, tradução nossa).

\footnotetext{
${ }^{2}$ Modelo, amplamente estudado por teóricos da informação, no qual quatro conceitos são associados, de modo contínuo, ao tratamento visual da informação: dado > informação > conhecimento > sabedoria.
} 
A visualização da informação, por sua vez, corresponde a uma modalidade de representação visual que, ao coletar, organizar e, principalmente, cruzar os dados, dilata a mente humana ao contribuir para amplificação do conhecimento sobre uma realidade significativa. Tornar a realidade visível e tangível, por meio da visualização da informação, pode interessar a todas as áreas do conhecimento. Na verdade, exemplos mais contundentes e expressivos do uso da visualização da informação para produzir conhecimento são justamente os que ultrapassam os limites do Design e da Comunicação e atingem atividades e saberes não habituados a pensar por meio da Comunicação Visual. Reside nesse ponto a grande inovação social de seu processo interdisciplinar: observamos um movimento em curso no qual as produções visuais estendem-se para além de artefatos digitais e tecnológicos constituindo-se como práticas culturais que envolvem vários campos do conhecimento, com foco direcionado, na sociedade da informação, para mapear e dar sentido às informações, em novos formatos. O caso a seguir ilustra o uso exemplar da visualização da informação aplicado a um tema relevância social.

Em fevereiro de 2006, Hans Rosling - médico, estatístico e professor de Saúde Internacional no Karolinska Institute (Suécia) - realizou uma apresentação no TED ${ }^{3}$ que se tornou referência no uso da visualização para aumentar a visibilidade e compreensão de temas de importância global. Na apresentação, chamada Stats that reshape your worldview ${ }^{4}$ ("Estatísticas que reformulam sua visão sobre o mundo"), de aproximadamente 20 minutos, Rosling apresenta dados estatísticos sobre saúde pública e desenvolvimento mundial de forma visual e inspiradora. Além de desmistificar alguns sensos-comuns sobre o tema, a partir de dados que revelam tendências e relações, a apresentação contribui para reforçar o papel que o Design e a Estatística desempenham nas mais variadas atividades e competências humanas. Para Rosling “... a Estatística não pertence somente ao domínio da especialização, mas também às mais simples e inspiradoras atividades do dia a dia com potencial de transformar a vida dos cidadãos."(ROSLING apud CAIRO, 2013, p. 309, tradução nossa). Poderíamos dizer o mesmo a respeito do Design da Informação.

\section{CENÁRIOS INOVADORES PARA A PRÁTICA DA VISUALIZAÇÃO DA INFORMAÇÃO}

Por um lado, percebemos o excesso de dados presentes em diversas esferas da vida social, por outro, evidenciam-se novas práticas e tecnologias que protagonizam uma transformação de âmbito descentralizador e transparente no processo comunicacional. Conjuntamente, volume de dados e novas práticas e tecnologias comunicacionais proporcionam um cenário para que visualização da informação, um especialidade do Design da Informação, emerja como potencial ferramenta para análise e significação de mensagens que podem contribuir para investigação e compreensão de diferentes contextos sócio-econômicos-culturais.

Diversas iniciativas e projetos atuais, das mais variadas temáticas e abordagens, utilizam a visualização da informação como processo de análise e apresentação de fenômenos. No entanto, consideramos particularmente interessante evidenciar as potencialidades de atuação da visualização da informação no que concerne a assuntos

\footnotetext{
${ }^{3}$ TED é a abreviação de Technology, Entertainment, Design. Criado em 1984, TED reúne uma série de conferências mundiais e locais sobre temáticas e ideias inovadoras.

${ }^{4}$ A apresentação está disponível em: $<$ http://www.ted.com/talks/hans_rosling_shows_the_best_stats_you_ve_ ever_seen.html >. Acesso em Mar. 2013.
} 
de interesse público e de inovação social. Nesse sentido, observamos um uso social do Design que acompanha práticas pioneiras em nossa sociedade como, por exemplo, o movimento open data, que apoia a transparência de dados da esfera pública ou privada, defendendo suas disponibilizações ao público, de maneira acessível e gratuita, para que possam ser livremente circulados e ressignificados. Essa tendência tem se consolidado com a difusão da internet e com o surgimento de inúmeras organizações, iniciativas independentes a favor da causa. No Brasil, a Constituição garante, pela Lei de Acesso à Informação, o direito de se requisitar informação de interesse público ao Estado e o dever de os agentes públicos disponibilizarem seus atos ${ }^{5}$ (ABRAMO, 2013). No entanto, o fato de a Lei ter sido implementada recentemente, em 2012, e ter permitido aos órgãos públicos a prerrogativa de gozar do direito à "informação sigilosa", abre-se espaço para que a legitimidade das fontes oficiais do Governo ser questionada em certas ocasiões. Por esses fatores, vemos surgir ferramentas independentes e on-line para distribuição e compartilhamento de dados como os portais The Data Hub, GitHub, ScraperWiki e o Freebase e outros mecanismos autônomos, como fóruns e lista de emails, que utilizam a inteligência coletiva da rede (LÉVY, 1998).

Estamos diante de um cenário de maior acesso à informação e de descentralização da comunicação por meio do qual os cidadãos, individual ou coletivamente, podem assumir posturas mais independentes e vigilantes na análise e significação de assuntos de interesse público e social. Destacamos quatro aspectos que, para além de artefatos tecnológicos, configuram-se como práticas culturais e permitem um processo comunicacional mais descentralizador e transparente:

- Estrutura de rede: caracteriza uma estrutura multidirecional, descentralizadora e hipertextual, que permite não só a circulação mais ampla e democrática da informação de interesse público, mas também a reutilização e redistribuição da informação disponível, o que poderá suscitar novas discussões e significações;

- Formatos abertos: caracteriza um modo de produção e disponibilização dos dados na rede de forma que os mesmos possam ser acessados, produzidos, extraídos e reutilizados por qualquer indivíduo gratuitamente. Aplicativos de softwares baseados na Web $\left(\mathrm{APIs}^{6}\right.$ ), como Google Docs e Google Fusion Tables, configuram-se como softwares de formatos abertos para a produção de conteúdo;

- Inteligência coletiva: designa práticas colaborativas em que a produção de determinado produto ou processo é desenvolvida por meio de contribuições individuais e articuladas para um objetivo em comum;

- Visualização da informação: finalmente, o Design exerce seu papel social ao possibilitar, pelos processos da visualização da informação, que os dados coletados sejam organizados, cruzados, analisados e apresentados em uma interface visualinterativa, transformando-se, então, em informações significativas, contextualizadas e transparentes para que os usuários-cidadãos possam ampliar seus conhecimentos.

\footnotetext{
5 Alguns canais oficiais de acesso à informação são: Portal da Transparência do Governo Federal (<http://www.portaldatransparencia.gov.br >), Transparência Brasil (<http://www.transparencia.org.br $>$ ) e Páginas da Transparência Pública (<http://www3.transparencia.gov.br/TransparenciaPublica>).

6 Application Programming Interface (API) ou Interface de Programação de Aplicativos é um conjunto de instruções e padrões de programação para acesso às funcionalidades e serviços de softwares baseados na Web, sem necessidade de implementação do software em si.
} 
Escolhemos um exemplo que consideramos relevante e atual para ilustrar como a visualização da informação pode ser empregada, junto aos outros aspectos citados, com a finalidade de ampliar a discussão, análise e significação sobre temas de interesse público e social. Fogo no Barraco ${ }^{7}$ é um projeto independente, aberto, colaborativo e disponibilizado na plataforma on-line, que objetiva investigar e evidenciar publicamente os inúmeros incêndios que acontecem em favelas paulistanas. A análise e apresentação dos dados, coletados de fontes jornalísticas, são realizadas em uma interface visualinterativa em que a modalidade de representação configura-se como uma visualização da informação. Nela, os dados a respeito dos incêndios em favelas são distribuídos em um plano geográfico, organizados por ano de ocorrência (de 2005 a 2014) e cruzados com outras camadas informativas (Valorização imobiliária, Favelas e Remoções/Operações Urbanas). Em entrevista ao jornal O Estado de S. Paulo, a idealizadora do projeto, a jornalista Patrícia Cornils, explicou que a iniciativa emergiu do desejo de compreender um problema de impacto político e socioambiental: "Queria entender uma porção de coisas: se estavam aumentando [os incêndios], onde eram mais frequentes, se havia relação entre as ocorrências e projetos urbanísticos da prefeitura." (CORNILS apud DIAS, 2012). Para isso, concebeu uma mídia em rede, aberta e coletiva em que dados sobre a ocorrência de incêndios em favelas, valorização imobiliária e operações urbanas na Grande São Paulo são coletados e organizados em uma planilha colaborativa disponibilizada pelo Google Docs (Fig 1):

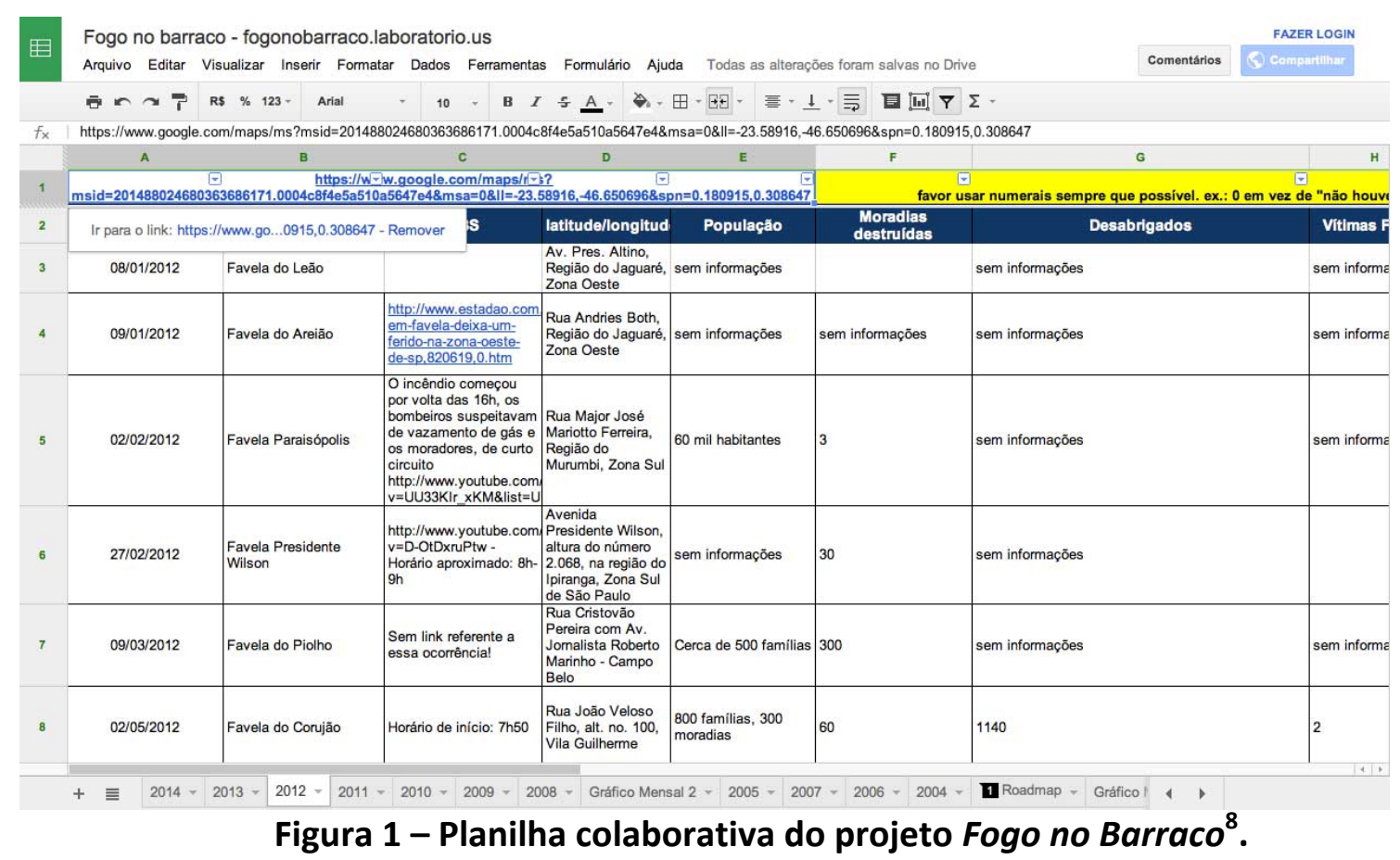

Os dados listados na planilha (Fig. 1), no entanto, não favorecem a análise e a comunicação de relações e comparações que possam evidenciar informações significativas e gerar conclusões. Por isso, a visualização da informação, como uma modalidade de

\footnotetext{
${ }^{7}$ Disponível em: <http://fogonobarraco.laboratorio.us> . Acesso em: mar. 2014.

${ }^{8}$ Imagem extraída da internet. Disponível em <https://docs.google.com/spreadsheet/ccc?key=0AmDIUHs6DSRYdEF ydXhrUE9wYjFtNINWN25yQm8ySkE\&hl=en_US\#gid=0>. Acesso em mar. 2014.
} 
representação gráfica, contribui para ampliar a cognição sobre um fenômeno públicosocial ao traduzir visualmente dados em evidências geográficas, temporais e quantitativas. A visualização da informação apresentada na Figura 2 corresponde à interface visualinterativa na qual os dados da planilha são visualizados e disponibilizados para que usuários interajam com os mesmos traçando percursos mais autônomos de navegação e significação sobre os dados, ainda que mediados pelas escolhas de gráfico-editoriais do projeto. A representação visual pode ser caracterizada como uma mapa de dados (Tufte, 1983), isto é uma representação georreferenciada ${ }^{9}$ em que dados sobre ocorrência de incêndio, localização de favelas e valorização imobiliária são mapeados conforme sua posição geográfica e organizados no tempo.
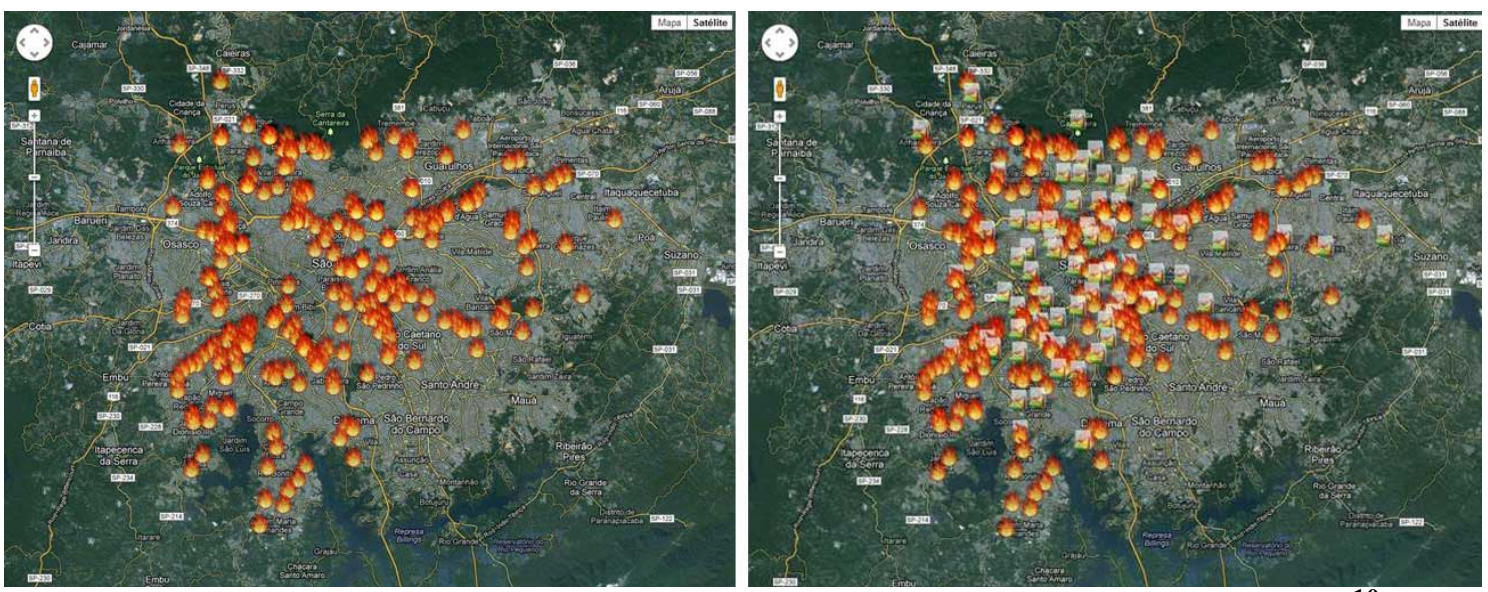

Figura 2 - Visualização da informação do projeto Fogo no Barraco ${ }^{10}$.

A Figura 2 evidencia duas possíveis configurações sintáticas da visualização da informação: na primeira, à esquerda, percebe-se a concentração de incêndio por localização espacial entre 2004 e 2012; na segunda, à direita, estabelece-se cruzamentos entre dois fenômenos distintos - ocorrência de incêndios em favelas e índice de valorização imobiliária na Grande São Paulo. Se há alguma efetiva ligação entre os incêndios e o preço dos imóveis, não há como realmente comprovar. No entanto, a visualização sugere apontamentos para hipóteses e argumentações que podem ser em seguida aprofundadas e investigadas. Por exemplo, em 2008, como destaca a matéria do O Estado de S. Paulo, “...houve um incêndio [no bairro da] Água Branca no mesmo ponto em que começou, naquele ano, uma das maiores valorizações imobiliárias da cidade" (DIAS, 2012). A Figura 3 apresenta uma configuração visual que evidencia a ocorrência do incêndio em uma favela no bairro da Água Branca, em 2008, e um gráfico que destaca a evolução da valorização imobiliária no mesmo local.

\footnotetext{
${ }^{9}$ Georreferenciamento de uma imagem, de um mapa ou qualquer outra forma de informação geográfica é tornar suas coordenadas conhecidas num dado sistema de referência.

${ }^{10}$ Imagem extraída da internet. Disponível em: <http://fogonobarraco.laboratorio.us> . Acesso em: mar. 2014.
} 
Fogo no barraco

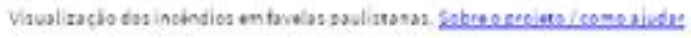
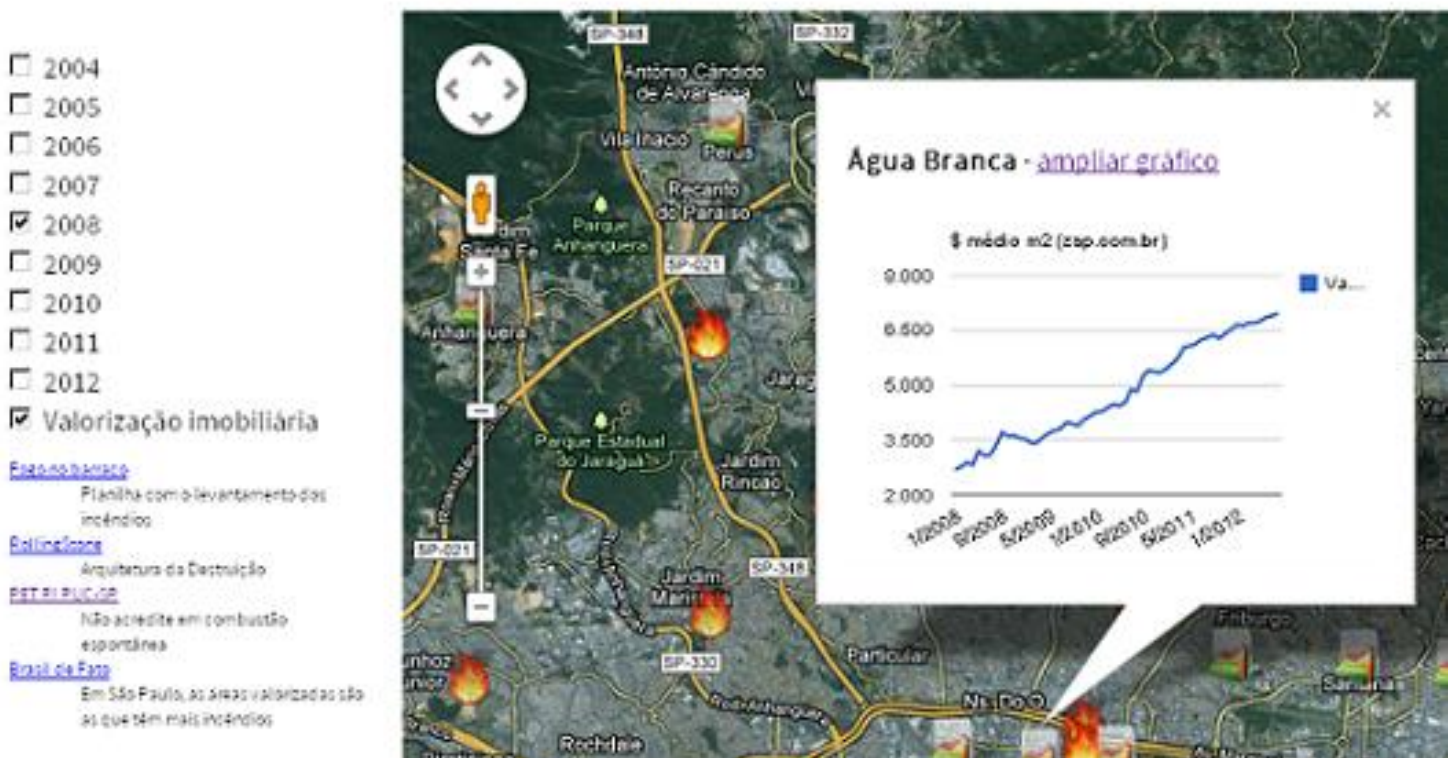

Figura 3 - Cruzamento entre ocorrência de incêndio e valorização imobiliária ${ }^{11}$.

\section{CONSIDERAÇÕES FINAIS}

A visualização da informação possibilita a análise de fenômenos complexos e ajuda a compreender o mundo ao nosso redor na medida em que torna visível relações de ordem, grandeza, evolução, simultaneidade, etc. entre dados de diferentes naturezas. Essa modalidade de representação visual articula competências do Design Gráfico e da Comunicação Social, entre outras disciplinas, possibilitando a criação de um produto visual, interativo que inclui o polo receptor no processo comunicacional, ao possibilitar que o usuário participe da exploração e geração de sentido.

O caráter comunicativo, exploratório e edificante da visualização da informação pode impactar as mais diversas áreas de atuação e do saber, das quais destacamos a esfera público-social que abrange a investigação e compreensão de contextos sócioeconômicos-culturais. O cenário, por um lado, de sobrecarga de dados e valorização da informação e, por outro lado, de descentralização da comunicação caracterizada pela estrutura de rede, formatos abertos e inteligência coletiva, constrói um ambiente profícuo para a emergência da visualização da informação como ferramenta com a qual os usuários podem analisar, interpretar e produzir significados para fenômenos de interesse público e social. Dessa forma os usuários podem assumir posturas mais cidadãs e independentes em um processo comunicacional descentralizador e transparente na qual o Design assume sua ênfase social.

\section{REFERÊNCIAS}

ABRAMO, Claudio Weber. Lei de Acesso à Informação no Brasil: um longo caminho a percorrer. IN: GRAY, J.; CHAMBERS, L.; BOUNEGRU, L. (Orgs.) Manual de Jornalismo de Dados. Open Knowledge Foundation, 2014. Disponível em: <http://datajournalismhandbook.org/pt/getting_data_2.html>. Acesso em: jan. 2014.

\footnotetext{
${ }^{11}$ Imagem extraída da internet. Disponível em: <http://fogonobarraco.laboratorio.us> . Acesso em: mar. 2014.
} 
BERTIN, Jacques. Semiology of Graphics: diagrams, networks, maps. Tradução William J. Berg. California: Esri Press, 2010.

BONSIEPE, Gui. Design as a Tool for Cognitive Metabolism: From Knowledge Production to Knowledge Participation. In: INTERNATIONAL SYMPOSIUM ON THE DIMENSIONS OF INDUSTRIAL DESIGN RESEARCH. 2000, Milão. Anais... 2000.

CAIRO, Alberto. Infografía 2.0: visualización interactiva de información en prensa. Madrid: Alamut, 2008.

CAIRO, A. The functional art: an introduction to information visualization graphics and visualization. Berkeley, CA: New Riders, 2013.

CARD, Stuart et. al. Readings in information visualization: using vision to think. São Francisco, California: Morgan Kaufmann Publishers, 1999.

CLEVELAND, William. The Elements of Graphing Data. Revised Edition. Summit, NJ: Hobart Press, 1994.

COSTA, Joan. La Esquemática. Barcelona: Paidós, 1998.

DERVIN, Brenda. Chaos, order, and Sense-Making: a proposed theory for information design. In: JACOBSON, R. (org.). Information Design. Cambridge: MIT Press, 2000. p. 35-57.

DIAS, Tatiana de Mello. Fogo no Barraco: 'estamos só começando'. O Estado de S. Paulo. 11 set. 2012. Disponível em: <http://blogs.estadao.com.br/link/fogo-nobarraco-estamos-so-comecando>. Acesso em mar. 2014.

DÜRSTELER, Juan Carlos. Visualización de información: una visita guiada. Barcelona: Ediciones Gestión 2000, 2003.

FEW, Stephen. Now you see it: simple visualization techniques for quantitative analysis. Oakland, California: Analytics Press, 2009.

FRASCARA, Jorge. ¿Qué es el disenõ de información?. 1a ed. Buenos Aires: Infinito, 2011.

HORN, Robert. Information Design: emergence of a new profession. In: JACOBSON, R. (org.). Information Design. Cambridge: MIT Press, 2000. p. 15-33.

JACOBSON, Robert. Introduction: Why Information Design Matters. In: JACOBSON, R. (org.). Information Design. Cambridge: MIT Press, 2000. p. 1-11.

LÉVY, Pierre. A inteligência Coletiva: por uma antropologia do Ciberespaço. São Paulo: Loyola, 1998.

THE ECONOMIST. Monstrous amount of data. 25 fev. 2014. Disponível em: <http://www.economist.com/node/15557421>. Acesso em jun. 2013.

TUFTE, Edward. The Visual Display of Quantitative Information. Cheshire, CT: Graphics Press, 1983.

WURMAN, Richard Saul. Ansiedade de informação: como transformar informação em compreensão. São Paulo: Cultura Editores Associados, 1991. 